\title{
Training and support of developing-country population scientists: A panel report-Summary and recommendations
}

Jane Menken

Ann K. Blanc

Cynthia B. Lloyd

Follow this and additional works at: https://knowledgecommons.popcouncil.org/departments_sbsr-pgy

Part of the Demography, Population, and Ecology Commons, and the Public Health Education and Promotion Commons

How does access to this work benefit you? Let us know!

\section{Recommended Citation}

"Training and support of developing-country population scientists: A panel report-Summary and recommendations." New York: Population Council, 2002. 
TRAINING AND SUPPORT of

DEVELOPING-COUNTRY POPULATION SCIENTISTS
$\mathbf{A}$
P A N E L
R E P O R T

Summary \& Recommendations 


\section{TRAINING AND SUPPORT of DEVELOPING-COUNTRY POPULATION SCIENTISTS}

A PANEL REPORT

Summary \& Recommendations

P O P U L A T I O N C O U N C I L 


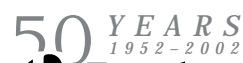 \\ 1 Population Council \\ One Dag Hammarskjold Plaza \\ New York, New York 10017 \\ tel 212-339-0500 \\ fax 212-755-6052 \\ e-mail pubinfo@popcouncil.org \\ www.popcouncil.org \\ The Population Council is an international, nonprofit, nongovernmental organization that seeks to improve the well-being and reproductive health of current and future generations around the world and to help achieve a humane, equitable, and sustainable balance between people and resources. The Council conducts biomedical, social science, and public health research and helps build research capacities in developing coun- tries. Established in 1952, the Council is governed by an international board of trustees. Its New York headquarters supports a global network of regional and country offices.}

(c) 2002 by The Population Council, Inc.

ISBN 0-87834-108-0

This summary report, also available in French and Spanish, is based on material in Jane Menken, Ann K. Blanc, and Cynthia B. Lloyd (eds.), Training and Support of Developing-Country Population Scientists: A Panel Report (New York: Population Council, 2002). The summary report is available for downloading in the three languages from the Population Council's Web site: www.popcouncil.org.

Single copies of the full Panel Report, in English only, may be obtained by writing to J ude Lam-Garrison at the Council's address given above or by e-mail: jlam-garrison@popcouncil.org. The publication is also available for downloading from www.popcouncil.org.

Any part of this report may be copied or adapted to meet local needs without permission from the Population Council, provided that the parts copied are distributed free or at cost (not for profit) and that the source is identified. Any commercial reproduction requires prior permission from the Population Council. The Population Council would appreciate receiving a copy of any materials in which any of the text is used. 
E rom its earliest days the Population Council has recognized the importance and value of training population scientists from developing countries. Since 1952, the Council's social science fellowship program has sustained a commitment to this goal; approximately 1,500 fellowships have been awarded for pre and postdoctoral training in population studies. While the demand for population scientists remains strong, the field has changed substantially since those early years.

An external group last evaluated the Council's fellowship program in 1979 so a review of the program was needed. But it was also particularly timely to conduct a broader assessment of the needs for training population scientists and an examination of the current situation. Population scientists are conducting research on new topics using new methodologies; the job market for population scientists has undergone significant changes; new donors have entered the population field and the priorities of established donors have shifted; and advances in and expanded access to technology have opened up new possibilities for training and research.

In light of these developments, the Mellon Foundation funded a project in 2000 to assess future needs for training and support of population scientists from developing countries. Under the project, an international panel of experts chaired by Jane Menken was assembled in September 2000. The members of the panel were J ane Bertrand, J ohn Cleland, Alex Ezeh, Chai Podhisita, Hoda Rashad, Luis Rosero-Bixby, Michael White, and Tukufu Zuberi. The Population Council's representative was Cynthia Lloyd, and Ann Blanc served as consultant to the panel.

The panel's mandate was to conduct a detailed examination of the current situation with respect to recruitment, training, funding, and employment of population scientists. On the basis of this assessment, the panel sought to identify gaps and areas of need and to make specific recommendations. To assemble information for their assessment, the panel collected material in a variety of ways. These included:

- two discussion groups with developing-country population scientists: at the 2001 Annual Meeting of the Population 
Association of America in Washington, DC and the 2001 IUSSP General Conference in Salvador, Brazil;

- interviews with current and former Population Council fellows, selection committee members, and representatives of institutions hosting fellows;

- commissioned case studies of the situation in China, India, and Uganda;

- informal assessments written by panel members and conference papers focusing on individual countries;

- participation of panel members in the IUSSP's Seminar on Demographic Training in the Third Millennium, held in Rabat, Morocco in May 2001;

- published and unpublished materials including previous assessments, journal articles, and foundation documents;

- informal discussions with people involved in the training and funding of international population experts.

The results of the panel's work are contained in a detailed report. ${ }^{1}$ The main conclusions and recommendations of that report are summarized in the present document.

${ }^{1} \mathrm{~J}$ ane Menken, Ann K. Blanc, and Cynthia B. Lloyd (eds.), Training and Support of Developing-Country Population Scientists: A Panel Report (New York: Population Council, 2002). 


\section{SUMMARY}

For some four decades, population scientists focused on describing and explaining population growth and fertility dedine. That era is now over. New global issues-the expansion of international migration, aging populations, persistent poverty, preservation of the environment, the HIVIAIDS epidemic-have significant demographic components. Because of its distinctive tools and perspective, the field of population studies is particularly well suited to understanding issues such as these and proposing effective solutions. The field strongly emphasizes empirical, evidence-based research. It focuses on clarifying both the population consequences of individual behavior and the effect of macro-level population processes on individuals. Explaining change is one of the field's central concerns.

Population studies first gained wide recognition in the 1950s when demographers documented rapid world population growth and described its causes. The perception of population growth as a grave social problem led to early investments by private foundations, international agencies, and national governments in the training of skilled demographers and other population scientists from developing countries to assume leadership roles in population research and policy formulation. Until the late 1980s, the policy orientation of population studies was confined mainly to the study of basic demographic processes (fertility, mortality, migration) and their social underpinnings. Gradually, population studies broadened considerably into areas that are equally critical to human welfare. The field today, while maintaining its core of basic demographic description, has embraced new areas such as education, reproductive health, and HIV/AIDS, and new dimensions of traditional population topics such as adolescence, gender, urbanization, migration, and the environment.

The field of population studies is interdisciplinary and has benefited from the insight of allied fields in the social and health sciences. Indeed, as its practitioners move into new areas, the historically interdisciplinary nature of the field has proven to be increasingly valuable. Yet, demography-the methodological core of 
the field - continues to be the central shaper and producer of population knowledge. The traditional tools of demography are being extensively drawn upon today as population scientists venture beyond their traditional areas of focus. The broadening of the field has also necessitated the acquisition of additional skills and familiarity with the concepts and tools of related disciplines. As governments grapple with a range of problems with population dimensions, there is an urgent need to adapt traditional models of training to prepare population scientists to work in a rapidly and continually changing environment.

A number of other developments are taking place as well. More and increasingly complex data sets are becoming widely available. Population scientists are using new methodologies ranging from qualitative techniques to sophisticated multivariate statistical methods. Research is increasingly focused on explanations of behavior at multiple levels that incorporate individual, household, and institutional factors, and on explaining changes over time. Advances in information technology have allowed research to be conducted at greater speed and lower cost, and the development of the Internet has created new opportunities for collaboration and information sharing.

Population experts in developing countries have traditionally been employed mainly in academic institutions and government. Yet the job market for population scientists has undergone significant changes in recent years as government structures are modified, universities evolve, and nongovernmental organizations acquire increasing importance. In general, the academic job market appears to be stagnant or declining, while in some countries the decentralization of government and reform of the health sector have increased the need for population experts at local levels of government. The private sector has also become a major employer of population experts in some locations and is potentially an important market in countries with an expanding commercial sector. A disparity between the requirements and needs of the job market and the supply of population experts with appropriate skills is evident in many developing countries. First, population scientists are struggling to keep up with new techniques required for the analysis of 
contemporary problems. Second, as a result of the contraction of training opportunities, older population scientists are not being adequately replaced by a new generation.

Because population research tends to focus on social problems and the search for their solution, donor priorities have an important influence on the field. Over time, new donors have entered the population field and the substantive priorities of established donors have shifted. Moreover, a critical change in the population field occurred in the mid-1990s when the United Nations Population Fund (UNFPA) and the United States Agency for International Development (USAID) decreased or eliminated funding for Ph.D. and Master's-level training. New donors have not compensated for the withdrawal of these established donors from the training arena, and those interested in capacity building generally confine themselves to short-term training. Opportunities for graduate training for promising developing-country scholars at developed-country institutions or at high-quality institutions in developing countries are now largely dependent on a diminishing number of private foundations and some national governments.

At present, the majority of Ph.D.-level population scientists from developing countries receive their degrees from universities in the developed world. In contrast, developing-country universities provide much of the Master's-level training. Local institutions are thus crucial in training the majority of those who are employed as population experts in developing countries. With few exceptions, these local academic institutions face substantial limitations on resources and are highly vulnerable to the shifting priorities of donors.

As the concerns of population scientists become more diverse and as institutions look beyond the limitations of their own programs, collaborative training programs are increasingly seen as an effective means of maximizing the training experience of students while potentially lowering overall costs. A number of universities have experimented with these alternatives to traditional models of advanced training in population studies. They include "sandwich" programs, in which Ph.D. students from developing-country universities receive some of their graduate training in a developed- 
country university; and joint programs, in which students attend classes at one or more universities that are members of a consortium. Advances in technology and expanded access to this technology have also opened up new possibilities for training. Various types of long-distance learning and research collaboration, access to virtual libraries, and Internet publishing are ways in which new technologies can be used for training.

In light of the preceding assessment of the current situation and needs for the future, the panel recommends the actions described below. While it is clear that the most desirable situation is one in which population experts are trained primarily in highquality institutions located in their own countries or regions, it is equally clear that this scenario is not likely to be achieved in the near future. Moreover, until career opportunities for trained population scientists improve in the developing world, many of those trained outside their own country may not return after their training is complete. The limited availability of resources dictates that choices be made. With this in mind, the following recommendations represent the panel's assessment of the actions that are most likely to lead to a more desirable situation while taking account of existing needs and gaps.

The recommendations focus on graduate-level education and support for highly trained population professionals. They are directed toward three of the primary actors in the training of population scientists: 1) universities providing graduate training in population, 2) professional associations of population scientists, and 3) donors supporting population scientists in developing countries. 


\section{RECOMMENDATIONS}

\section{Universities Providing Graduate Training in Population}

1. Ensure that all population scientists at the Master's and Ph.D. levels acquire a core body of demographic knowledge.

Population studies are distinguished by a core body of demographic knowledge and techniques. This demographic core consists of an understanding of population composition, how it changes, and the determinants and implications of change, as well as basic research methods such as sampling, data collection, measurement and interpretation of demographic indicators, and multivariate statistical analysis. Because much of the demographic literature is published in English, learning this core requires an adequate reading knowledge of English. All Master's and Ph.D. programs in population should provide a core set of courses in demography staffed by faculty with specialized training. All graduate students who want to become practitioners in the population field should master this core of knowledge.

2. Offer multidisciplinary training for population scientists.

In the past, demographers successfully described population growth and fertility dedine. Now, population scientists emphasize new priorities including HIV/AIDS, gender issues, aging, reproductive health, adolescence, urbanization, migration, poverty, and the environment. Population scientists have distinctive contributions to make to all of these, but to be most effective they either have to work alongside people from other disciplines or be trained in these other disciplines.

The panel recommends that curricula be modified to familiarize trainees with key concepts and methodologies from allied disciplines, especially economics, sociology, statistics, and public health. There is also a need to modify training curricula to reflect changes in the substantive interests of population studies. The burden on the resources and staff of universities implied by such expansion suggests that programs might choose to specialize in selected areas. 
3. Ensure the availability of advanced-level training in formal demography for a small number of specialists at university-based centers of excellence. While all population scientists should have a basic grounding in the knowledge and techniques of population science, advanced training in formal demography is required for a smaller number of specialists. These specialists are crucial for performing some of the key functions of traditional demography, including population estimates and projections, methodological development, and modeling. Neither the demand nor the expertise exists in all countries or universities to provide such training.

The panel recommends that training in formal demography be provided by a network of university-based centers of excellence that commit themselves to specializing in this area. Long-distance courses in formal demography could be highly effective tools for offering training to students outside these centers. Universities with a commitment to excellence in formal demography need to attract and retain a core faculty specializing in this discipline, to develop an appropriate curriculum, and to accept students from other universities for a period of specialized training.

\section{Improve training through transnational collaborations.}

International collaboration is increasingly recognized as an important component of training for population scientists. Successful examples include interregional and intraregional programs, collaborative research and training programs pairing universities with programs at different levels of development, and collaborations between universities and demographic surveillance sites. The participation of population scientists in significant collaborative research projects has also proven to be highly beneficial for training and career development. The panel encourages those involved in training to think creatively about ways to make training programs more effective through collaboration and recommends that donors make the funding of such programs a priority.

5. Provide previously trained population scientists with opportunities for continuing education.

One of the strengths of the field of population sciences is that it 
responds quickly to new issues. But population scientists with Master's and Ph.D.-level training who work in relative isolation experience great difficulty in keeping up with these changes, learning new techniques, and expanding their substantive knowledge.

Midcareer training for experienced professionals-a form of continuing education-would help reduce these problems and enable teachers in developing-country universities to maintain upto-date curricula in their own countries or regions. This type of training also helps participants to build useful personal networks and institutional links. The panel recommends that universities provide extended training opportunities in the form of midcareer fellowships and visiting faculty exchanges lasting six to 12 months. In addition, universities should provide short-term options lasting less than six months that provide high-quality training on special topics to population professionals at different stages of their careers. In addition to substantive topics, these could include courses on teaching, computer skills, new methodologies, and the presentation and dissemination of research findings. Long-distance courses are likely to be appropriate models for some types of midcareer training. It is important that these programs be targeted to those professionals who are most likely to benefit from them and who are employed in institutions where they can use the skills acquired.

\section{Professional Associations of Population Scientists}

\section{Encourage international participation in professional meetings} and associations.

Past reviews of training have uniformly commented on the professional isolation experienced by young developing-country scholars returning to their home countries from institutions in the developed world. A similar observation can be made today about young researchers and their mentors within developing countries, especially large countries with multiple demographic research centers, such as China and India. It is crucial that there be continuing contact between young and established researchers and increased access to current 
research findings. The Population Association of America has maintained a successful program of travel awards for participation in its annual meetings by developing-country population scientists. The International Union for the Scientific Study of Population has also provided invaluable opportunities for international scholarly exchange at its seminars and conferences. These programs need continued support. The availability of travel funds to other international and regional population associations could provide these benefits to larger numbers of developing-country population scientists.

Membership in professional associations and participation in professional meetings are important ways to maintain networks and gain access to the latest research findings and the newest research techniques. These benefits are particularly important for allowing junior researchers to establish themselves within the international research community. Professional associations can be even more effective now with the ease of communication offered by the Internet. These associations should take full advantage of this technology to maximize benefits for its members, especially those from developing countries.

\section{Donors supporting population scientists in developing countries}

7. Develop donor consortiums to provide long-term support to selected universities in the developing world to create centers of excellence for the training of population scientists.

The long history of failed attempts to support developing-country training institutions has yiel ded a number of lessons. First, in order to be sustainable, training institutions with few exceptions must be firmly rooted in universities. Second, a long-term commitment is required. Funding should be aimed at developing high-quality research centers responding to a locally determined research agenda. Because access to the population studies literature is otherwise severely limited, offering English-language training is essential. In general, support should be aimed at improving the sustainability of local institutions through the retention of local staff and the reversal of "brain drain" to developed countries. 
The most important elements of support are research grants, computer facilities, libraries, travel grants, and funding for transnational collaborations that include faculty exchanges. Because such investments are both long term and expensive, the most effective strategy is to focus on a small number of carefully selected universities starting with those that have a base of local support and the potential for strong leadership. Indeed, a number of developingcountry institutions have become successful, sustainable centers for training and research. Finally, and perhaps most importantly, institutions require local support in order to survive in the long term. Excessive dependence on the support of foreign donors leaves institutions vulnerable to the vagaries of changing donor priorities (which may or may not be relevant to individual country priorities) and to fluctuations in funding levels. Donors can usefully offer support to local institutions as they seek to raise and sustain domestic government or private-sector funding.

8. Provide technology grants to university training centers in developing

countries to support computer purchases, equipment upgrades, software purchase and support, and Internet connectivity.

Technological advances make it increasingly feasible to reduce isolation. Access to the Internet is essential. It permits continued contact between long-distance collaborators and easy access to virtual libraries and to long-distance learning. The establishment of regional networks of researchers for sharing information, findings, and training materials via the Internet has al so proven to be feasible and effective. The panel therefore strongly recommends that donors support initiatives to increase this type of contact and access. It may be appropriate to designate a few institutions or groups to hel p provide technology access. More grant programs for institutions to obtain access to virtual libraries would also be useful.

9. Support the creation and expansion of virtual libraries and experimentation with long-distance learning opportunities.

Access to the latest findings and materials across relevant fields is critical for conducting research in population studies and for uni- 
versities to produce well-trained graduates. The potential of webbased libraries and archives for expanding access to this information in developing countries has just begun to be tapped. The panel encourages donors to make increased investments in the creation, expansion, and consolidation of virtual libraries with materials relevant to developing-country population scientists. In order to encourage the fullest possible use of these new resources, donors should take into account different levels of access to the Internet among countries and institutions.

A number of long-distance learning opportunities in population science are already available or under development. These range from traditional correspondence courses to instruction via video links to electronic or web-based materials. The content of long-distance learning can range from technical topics in demography to teaching support. The panel believes that long-distance learning holds great promise for the training and support of developing-country population scientists and recommends that donors provide funding to improve, expand, and evaluate its impact and cost-effectiveness.

10. Fund Ph.D. fellowships at appropriate developed-country universities that give priority to promising students from developing countries who do not have access to local centers of excellence.

The need for Ph.D.-level population scientists remains substantial in developing countries, but the gap between need and funding has increased as a number of donors have reduced or eliminated support. The consequences of this reduction are already apparent, with some institutions observing a dedine in both the number and the quality of candidates applying for advanced training. It is clear, for example, that the supply of qualified sub-Saharan African candidates for Ph.D. training has diminished substantially with the demise of important regional training centers. Short-term training is an inadequate substitute for the skills and capabilities-especially the ability to think analytically and critically-that are acquired during an extended period of advanced study. 
The panel recommends that foundations, agencies of the United Nations, and individual countries reevaluate their programs and target some funding to long-term training leading to the Ph.D. Because the majority of the highest-quality population training programs are located in developed-country universities, it is appropriate, at least in the short term, that some of this funding be made available to developing-country students studying abroad. This funding should be used wisely so that it benefits the most promising scholars studying at the most appropriate institutions. Such training can also be made more cost-effective and could possibly increase the fraction of trainees who remain in their home country by shortening the period spent abroad, perhaps through the increasing use of "sandwich" or collaborative programs.

It is vitally important that universities that commit themselves to training developing-country population scientists be responsive to developing-country concerns by having faculty with appropriate expertise and experience and by offering courses and research opportunities that are relevant to the needs of the trainees' countries of origin. 
5 P $\underset{1952-2002}{Y A R S}$

1P Population Council

One Dag Hammarskjold Plaza

New York, New York 10017

www.popcouncil.org 